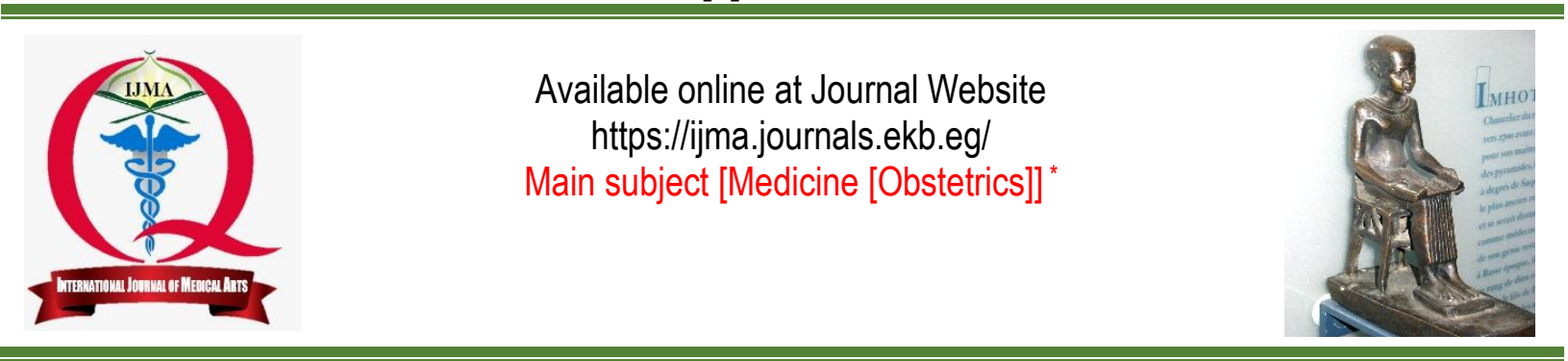

Original article

\title{
Ondansetron Compared with Doxylamine and Pyridoxine for Treatment of Nausea and Vomiting in Pregnancy
}

\author{
Mohamed Kamal Yahia ${ }^{[1]}$, Khattab Abdelhalim Omar Khattab[2], Alaa Ebrahim Hamed[2] \\ Department of Obstetrics and Gynecology, Damietta General Hospital, Ministry of Health, Egypt ${ }^{[1]}$ \\ Department of Obstetrics and Gynecology, Damietta Faculty of Medicine, Al-Azhar University, Egypt ${ }^{[2]}$
}

Corresponding author

Moahmed Kamal Yahia

Email: hamzamohammedkamal89@gmail.com

Received at: March 22, 2020; Revised at: June 24, 2020; Accepted at: June 25, 2020; Available online at: June 25, 2020

DOI: $10.21608 / i j m a .2020 .26371 .1111$

\begin{abstract}
Background: Nausea and vomiting affects up to $80 \%$ of the pregnant women population and are the third leading causes of maternal hospitalization during pregnancy. Many pregnant females, and even some healthcare professionals, dread using antiemetic drugs due to a false belief of their teratogenic risk.

Aim of the work: This study aimed to evaluate ondansetron to a combination of doxylamine and pyridoxine in controlling pregnancy-related nausea and vomiting.

Patients and Methods: This randomized controlled trial included 156 pregnant women, at 16 weeks of gestation, with mild-tomoderate nausea and vomiting. Meanwhile, women with severe symptoms indicating admission, those already on anti-emetics, and those who wouldn't be able to show up for follow-up visits were excluded. Seventy-eight patients received intravenous injection of ondansetron [Zofran] at a dose of $8 \mathrm{mg}$ once daily for 5 days, whereas the other 78 patients received oral pyridoxine at a dose of $25 \mathrm{mg}$ plus doxylamine at a dose of $12.5 \mathrm{mg}$ [Diclegis] twice daily for 5 days. Each patient was subjected to full history taking, complete clinical examination and investigations.
\end{abstract}

Results: Women on Ondansetron reported better alleviation of nausea compared to those receiving pyridoxine and doxylamine $[96.2 \%$ vs. $52.6 \%, P<0.001$, respectively]. The most frequently reported side effects were headache, dry mouth, gastrointestinal [GI] disturbances, and abdominal pain, and the differences in their occurrence between the two groups were statistically insignificant.

Conclusion: Ondansetron was found superior to the combination of pyridoxine and doxylamine in improving pregnancy-related nausea and vomiting occurring without a significant increase in side effects.

Keywords: Nausea; Vomiting; Doxylamine; Ondansetron; Pregnancy.

This is an open access article under the Creative Commons license [CC BY] [https://creativecommons.org/licenses/by/2.0/]

Please cite this article as: Yahia MK, Khattab AOK, Hamed AE. Ondansetron Compared with Doxylamine and Pyridoxine for Treatment of Nausea and Vomiting in Pregnancy. IJMA 2020; 2[3]: 611-618.

* Main subject and any subcategories have been classified according to research topic. 


\section{INTRODUCTION}

Nausea and vomiting of pregnancy [NVP] reported in up to $80 \%$ of pregnant females ${ }^{[1]}$. Mild form of NVP affects the quality of life of these females and their family, but, severe degree [known as hyperemesis gravidarum; $\mathrm{HG}$, led to electrolyte imbalance, dehydration and the sever form needs hospitalization[2].

The therapeutic interventions for NVP are symptomatic. An evidence exists about the fetal safety of different antiemetic drugs, females and healthcare professionals are often hesitant to use antiemetics due to a false belief of teratogenic risk[3].

Treatment depended on relieving symptoms and preventing danger morbidity such as renal impairment, Wernicke encephalopathy and also extreme loss of weight[4]. Treatment can be classified into three categories. First-line category, including simple changes in lifestyle [such as eating a small amount, avoiding dietary triggers and strong odors, high-carbohydrate intake, [low-fat foods] and overthe-counter remedies, as ginger and vitamin B6 [pyridoxine]. Second-line drugs are typically prescribed for a female at her first presentation to medical care facility, usually by an obstetrician, and comprise a range of antiemetic medications as well as the provision of intravenous fluid with electrolyte for female who are dehydrated and ketotic. Third-line category are indicated for female with severe or persistent symptoms and this management need hospital setting. In this category corticosteroids and supportive therapy as, enteral feeding allowed $[5]$.

Vitamin B6 as pyridoxine can be prescribed for improvement of manifestations with mild to moderate NVP. The American College of Obstetrics and Gynecology considers it [vitamin B6] as a first-line therapeutic modality for NVP. Vitamin B6 plus the medication doxylamine, are recommended for females that not improved by vitamin B6 alone. Vitamin B6 [pyridoxine] plus the medication doxylamine is less effective than the medication ondansetron[6].

Ondansetron is a drug used to prevent nausea and vomiting caused related to motion sickness. It can be given by mouth, or by injection into a muscle or into a vein. Ondansetron can be administered for treatment of morning sickness and also hyperemesis gravidarum of pregnancy. It is typically used after trials of other drugs have not success [7].

Ondansetron categorized in category $B$ in the united states when indicated to be used in pregnancy. It is not known if ondansetron is excreted in breast milk. VitaminB6 [Pyridoxine]/ Doxylamine Combination. Koren et al. ${ }^{[8]}$ compared pyridoxine [10mg] plus doxylamine [10mg, slow-release preparation] with placebo over 14 days. Symptoms disappeared in both groups, but the improvement was greater in the pyridoxine-doxylamine group. Oliveira et al.[9] did their study to compare pyridoxine-doxylamine with ondansetron. They reported that ondansetron led to improvement of symptom more than females in pyridoxinedoxylamine group. This study was done for the first time on Egyptian women with an average sample size which gives us significant results.

\section{AIM OF THE WORK}

The aim of our study was to compare whether ondansetron or the combination of doxylamine and pyridoxine is the best treatment for nausea and vomiting of pregnancy.

\section{PATIENTS AND METHODS}

This was a randomized [computer system] controlled study conducted in Al-Azhar University hospital [New Damietta] and Damietta General Hospital. This study included 156 women with nausea and vomiting of pregnancy and started at the period from January 2019 to December 2019 and participated after oral and informed consent.

The present study had the following criteria; Age of women more than 18 years old and the age of pregnancy more than 16 weeks of gestation [the gestational age detected by last menses or ultrasonography] and women with mild to moderate nausea and vomiting associated with pregnancy.

All of the following criteria were excluded; women with sever degree of nausea and vomiting associated with pregnancy that need hospitalization, female using anti-emetics drugs [as ondansetron, metoclopramide, doxylamine, pyridoxine, or promethazine], women had an allergy to any medication that used in this study, women unable to return to visit us 1 week after for a follow-up and they were unable to obtain the medications on the day of enrollment.

Methods: Patients eligible for the study was 
underwent the following: full history, complete examination including general, abdominal and pelvic examination.

Study design: 156 women with nausea and vomiting of pregnancy were assigned to $8 \mathrm{mg}$ of ondansetron plus a placebo tablet or $25 \mathrm{mg}$ pyridoxine plus $12.5 \mathrm{mg}$ of doxylamine for 5 days.

\section{Patient in the study divided randomly into two groups:}

Group [l]: 78 patients with nausea and vomiting treated with intravenous injection of ondansetron [Zofran] at a dose $8 \mathrm{mg}$ once daily for 5 days.

Group [II]: 78 patients with nausea and vomiting treated with oral pyridoxine at a dose $25 \mathrm{mg}$ plus doxylamine at a dose $12.5 \mathrm{mg}$ [vomidoxine] twice daily for 5 days.

\section{Drugs:}

Zofran had been purchased from [Novartis Pharmaceuticals Company] and given at adose of at a dose $8 \mathrm{mg}$ once daily for 5 days.

Vomidoxine had been purchased from [Pharaonia Pharmaceuticals Company] and considered a drug of pyridoxine at a dose $25 \mathrm{mg}$ plus doxylamine at a dose $12.5 \mathrm{mg}$ and given twice daily for 5 days.

- The collected blood samples were kept in dry clean graduated plastic centrifuge tubes until coagulated, then set to the centrifuge at 5000 rotations per minute for about 15 minutes to separate the serum.

- Most of the serum was sucked out into Eppendorf tubes and stored frozen at $-200 \mathrm{C}$ till used for the determination of: Aminotransferases [ALT \& AST] [10], Blood urea nitrogen [BUN][11] and Creatinine[12].

\section{Outcome measures [35]}

- The primary outcome is the improvement in nausea as reported on Pregnancy-Unique Quantification of Emesis and Nausea [PUQE].

- Secondary outcomes are the reduction in vomiting on the Pregnancy-Unique Quantification of Emesis and Nausea [PUQE] and the proportion of patients reporting sedation or constipation while using either study regimen.

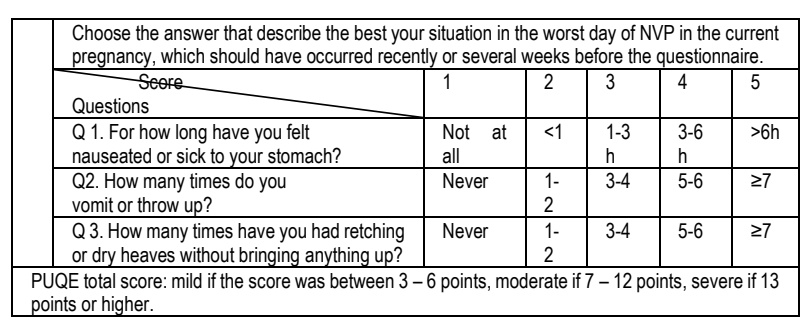

\section{Ethical consideration}

1- Study protocol was submitted for approval by Institution Research Board [IRB00012367] [19-01002] of the Faculty of Medicine, Al-Azhar University [Damietta].

2- Informed consent of the hospital authorities.

3- Informed verbal consent was obtained from each participant sharing in the study.

4- Confidentiality and personal privacy was respected in all levels of the study. Collected data not be used for any other purpose

Statistical analysis: The collected data were fed to a personal computer (excel sheet), then analyzed using statistical package for social sciences [SPSS] version 19 [IBM®SPSS $\circledast$ Inc, Chicago, USA] . Quantitative data were expressed as the mean \pm standard deviation [SD]. Qualitative data were presented as relative frequency and percent distribution. For comparison between two groups, the independent samples [t] test. For comparison between categorical groups, the student $T$ test was used. For all tests, $P$ values $<0.05$ were considered significant. For all tests, $\mathrm{P}$ values $>0.05$ were considered insignificant

\section{RESULTS}

In the present study, Age, weight, body mass index [BMI], gestational age and hospital stay were nearly comparable between studied cases with nonstatistically significant differences. Age; $23.63 \pm 2.29$ years in group I versus $24.14 \pm 2.53$ years in group II, weight; $76.91 \pm 8.29 \mathrm{~kg}$ versus $77.43 \pm 8.17 \mathrm{~kg}$, BMl; $28.06 \pm 0.94 \mathrm{~kg} / \mathrm{m}^{2}$ versus $27.93 \pm 1.3 \mathrm{~kg} / \mathrm{m}^{2}$, gestational age; $11.9 \pm 2.59$ weeks versus $11.26 \pm 2.4$ weeks and hospital stay at time of the study design; $2.01 \pm 1.03$ day versus $2.1 \pm 0.84$ day with nonstatistical significant differences [Table 1].

In the present study, there were 3 women [3.8\%] with Previous nausea \& vomiting [N\&V] in group I versus $5[6.41 \%]$ in group II, 4 [5.13\%] with diabetes mellitus [DM] versus 6 [7.69\%], 6 [7.69\%] with 
hypertension [HTN] versus 5 [6.41\%] and 2 [2.56\%] with pregnancy at intra-uterine device [IUD] versus 1 [1.28\%], respectively with non-statistical significant differences [Table 2].

In the present study, ALT, AST, urea and creatinine was nearly comparable between studied cases with non- statistically significant differences. ALT; $30.42 \pm 2.8 \mathrm{mg} / \mathrm{dl}$ in group I versus $29.89 \pm 4.07$ $\mathrm{mg} / \mathrm{dl}$ in group II, AST; $25.36 \pm 3.04 \mathrm{mg} / \mathrm{dl}$ versus $24.85 \pm 3.46 \mathrm{mg} / \mathrm{dl}$, urea; $24.35 \pm 2.5 \mathrm{mg} / \mathrm{dl}$ versus $23.54 \pm 3.49 \mathrm{mg} / \mathrm{dl}$ and creatinine; $0.95 \pm 0.15 \mathrm{mg} / \mathrm{dl}$ versus $0.98 \pm 0.19 \mathrm{mg} / \mathrm{dl}$, respectively with nonstatistical significant differences [Table 3].

Regarding side effects in the present study, there were 10 women [12.82\%] with headache in group I versus 11 [14.1\%] in group II, 4 [5.13\%] with dizziness versus 3 [3.8\%], 5 [6.41\%] with fatigue versus 4 [5.13\%], 0 [0.0\%] with syncope versus 1 [1.28\%], 3 [3.8\%] with insomnias versus [4 [5.13\%],
3 [3.8\%] with back pain versus 4 [5.13\%], 10 [12.82\%] with dry mouth versus 14 [17.94\%], 13 [16.67\%] with gastro-intestinal [GIT] disorders versus 8 [10.26\%], 12 [15.38\%] with abdominal pain versus 11 [14.1\%] and 1 [1.28\%] with rashes versus $2[2.56 \%]$, respectively with non-statistical significant differences [Table 4].

In the present study, there were 2 women [2.56\%] with missed abortion in group I versus 2 [2.56\%] in group II, 3 [3.8\%] with spontaneous abortion versus 4 [5.13\%] and 2 [2.56\%] with premature rupture of membrane [PRM] versus 3 [3.8\%] respectively with non-statistically significant differences. There were significant improvements of patients with nausea and vomiting that treated with ondansetron when compared with patient treated with pyridoxine and doxylamine [75 women [96.2\%] in group I versus 41 [52.6\%] in group II [Table 5].

Table [1]: Demographic data of the studied cases

\begin{tabular}{|c|c|c|c|c|}
\hline Parameters & Group I & Group II & T test & p value \\
\hline $\begin{array}{c}\text { Age [years] } \\
\text { Mean } \pm S D ; \text { Range }\end{array}$ & $23.63 \pm 2.29 ; 19-29$ & $24.14 \pm 2.53 ; 19-29$ & 1.33 & 0.19 \\
\hline $\begin{array}{c}\text { Weight [Kg] } \\
\text { Mean } \pm S D ; \text { Range }\end{array}$ & $76.91 \pm 8.29 ; 62-91$ & $77.43 \pm 8.17 ; 63-98$ & 0.39 & 0.69 \\
\hline $\begin{array}{c}\text { BMI [kg/m2] } \\
\text { Mean } \pm S D ; \text { Range }\end{array}$ & $28.06 \pm 0.94 ; 25.5-30.1$ & $27.93 \pm 1.3 ; 25.3-30.2$ & 0.75 & 0.46 \\
\hline $\begin{array}{c}\text { Gestational age [weeks] } \\
\text { Mean } \pm S D ; \text { Range }\end{array}$ & $11.9 \pm 2.59 ; 7-15$ & $11.26 \pm 2.4 ; 7-15$ & 1.7 & 0.09 \\
\hline $\begin{array}{c}\text { Hospital stay [days] } \\
\text { Mean } \pm S D ; \text { Range }\end{array}$ & $2.01 \pm 1.03 ; 1-4$ & $2.1 \pm 0.84 ; 1-4$ & 0.59 & 0.55 \\
\hline
\end{tabular}

Table [2]: Comparison between studied cases regarding history

\begin{tabular}{|l|c|c|c|c|}
\hline \multicolumn{1}{|c|}{ Parameters } & $\begin{array}{c}\text { Group I } \\
{[78]}\end{array}$ & $\begin{array}{c}\text { Group II } \\
{[\mathbf{7 8}]}\end{array}$ & Z score & p value \\
\hline Previous nausea \& vomiting & $3[3.8 \%]$ & $5[6.41 \%]$ & 0.73 & 0.46 \\
\hline DM & $4[5.13 \%]$ & $6[7.69 \%]$ & 0.66 & 0.52 \\
\hline HTN & $6[7.69 \%]$ & $5[6.41 \%]$ & 0.31 & 0.76 \\
\hline IUD & $2[2.56 \%]$ & $1[1.28 \%]$ & 0.58 & 0.56 \\
\hline
\end{tabular}

Table [3]: Laboratory data of the studied cases

\begin{tabular}{|c|c|c|c|c|}
\hline Parameters & Group I & Group II & $\mathrm{T}$ test & $p$ value \\
\hline $\begin{array}{l}\text { ALT [mg/dl] } \\
\quad \text { Mean } \pm S D ; \text { Range }\end{array}$ & $30.42 \pm 2.8 ; 24.5-33.9$ & $29.89 \pm 4.07 ; 2.1-38.2$ & 0.94 & 0.35 \\
\hline $\begin{array}{l}\text { AST [mg/dl] } \\
\quad \text { Mean } \pm S D ; \text { Range }\end{array}$ & $25.36 \pm 3.04 ; 20.8-30.5$ & $24.85 \pm 3.46 ; 19.5-31.8$ & 0.97 & 0.33 \\
\hline $\begin{array}{l}\text { Urea [mg/dl] } \\
\quad \text { Mean } \pm S D ; \text { Range }\end{array}$ & $24.35 \pm 2.5 ; 15.9-29.5$ & $23.54 \pm 3.49 ; 16-30.4$ & 1.66 & 0.1 \\
\hline $\begin{array}{l}\text { Creatinin [mg/dl] } \\
\text { Mean } \pm S D ; \text { Range }\end{array}$ & $0.95 \pm 0.15 ; 0.5-1.2$ & $0.98 \pm 0.19 ; 0.7-1.3$ & 1.68 & 0.09 \\
\hline
\end{tabular}


Table [4]: Reported side effects of the studied cases

\begin{tabular}{|l|c|c|c|c|}
\hline \multicolumn{1}{|c|}{ Parameters } & $\begin{array}{c}\text { Group I } \\
{[\mathbf{7 8}]}\end{array}$ & $\begin{array}{c}\text { Group II } \\
{[\mathbf{7 8}]}\end{array}$ & Z score & p value \\
\hline Headache & $10[12.82 \%]$ & $11[14.1 \%]$ & 0.82 & 0.23 \\
\hline Dizziness & $4[5.13 \%]$ & $3[3.8 \%]$ & 0.69 & 0.38 \\
\hline Fatigue & $5[6.41 \%]$ & $4[5.13 \%]$ & 0.73 & 0.34 \\
\hline Syncope & $0[0.0 \%]$ & $1[1.28 \%]$ & 0.32 & 1.003 \\
\hline Insomnias & $3[3.8 \%]$ & $4[5.13 \%]$ & 0.69 & 0.38 \\
\hline Back pain & $3[3.8 \%]$ & $4[5.13 \%]$ & 0.69 & 0.38 \\
\hline Dry mouth & $10[12.82 \%]$ & $14[17.94 \%]$ & 0.37 & 0.88 \\
\hline GIT disorders & $13[16.67 \%]$ & $8[10.26 \%]$ & 0.24 & 1.17 \\
\hline Abdominal pain & $12[15.38 \%]$ & $11[14.1 \%]$ & 0.82 & 0.23 \\
\hline Rashes & $1[1.28 \%]$ & $2[2.56 \%]$ & 0.56 & 0.58 \\
\hline
\end{tabular}

Table [5]: Comparison between studied cases regarding abortion, premature rupture of membranes and improvement of nausea.

\begin{tabular}{|l|c|c|c|c|}
\hline Parameters & $\begin{array}{c}\text { Group I } \\
{[78]}\end{array}$ & $\begin{array}{c}\text { Group II } \\
{[78]}\end{array}$ & Z score & p value \\
\hline Missed abortion & $2[2.56 \%]$ & $2[2.56 \%]$ & --- & ---- \\
\hline Spontaneous abortion & $3[3.8 \%]$ & $4[5.13 \%]$ & 0.69 & 0.38 \\
\hline PRM & $2[2.56 \%]$ & $3[3.8 \%]$ & 0.65 & 0.46 \\
\hline Improvement of nausea & $75[96.2 \%]$ & $41[52.6 \%]$ & 6.23 & $<0.001^{*}$ \\
\hline
\end{tabular}

\section{DISUCSSION}

The present work aimed to compare whether ondansetron or the combination of doxylamine and pyridoxine is superior for the treatment of nausea and vomiting of pregnancy. Regarding side effects in the present study, headache, dizziness, fatigue, syncope, insomnias, back pain, dry mouth, gastrointestinal [GIT] disorders, abdominal pain and rashes were nearly comparable with non-statistically significant differences between both groups.

The commonest side effects of ondansetron include headache [8-42\%], elevation of transaminases [17\%], diarrhea [2-5\%], xerostomia [5$17 \%$, dizziness [5\%] and constipation. Extrapyramidal reactions have been observed at $<1 \%$ in adults while two cases were reported in children [13]. Anorexia, changes in blood pressure and heart rate, blurred vision, paresthesia and fever are rare [14]. Fatigue is associated with NVP in several studies [1516]. Also, agreed with Yokoi et al. [17] who noticed that the main side effects ondansetron were dizziness, headache and drowsiness. In addition, when considering the maternal safety that associated with first trimester, manifestations such as tendency to sleep, fatigue \& dehydration, may be inaccurately linked to the medication, rather than to pregnancy and/or NVP. The use of doxylamine plus pyridoxin was not linked to an increased risk of any side effects when compared to one, lending important reassurance to its use by large numbers of pregnant women[18]. In the present study, missed abortion, spontaneous abortion and premature rupture of membrane [PRM] were nearly comparable with nonstatistical significant differences between both groups. A large retrospective study done by [19] from the Danish birth that include 608385 pregnancies and this study found no higher risk of major stillbirth, birth defect, small-for-gestational age and preterm labour. NVP has been linked to decreased risk of miscarriages, premature birth, and small for gestational age newborns, suggesting that NVP may have a protective effect on the fetus [20]. Dodds et al. [21] showed that females with NVP had an increased risk of preterm delivery and also low birth weight. Meta-analyses reported that the use of combined pyridoxine plus doxylamine during pregnancy is not associated with the increased incidence of any birth defects [9]. Capp et al. [22] done their work on 36 women that half of them treated by ondansetron and other half treated by a combination of pyridoxine and doxylamine. They reported that there were not significantly changes between the both groups regarding demographic data. Pasternak et al. ${ }^{[19]}$ reported that in a cohort of 608,385 pregnancies, ondansetron was not associated with an increased or significant risk of spontaneous abortion, stillbirth, major birth defects, preterm delivery, or delivery of a low birth- weight neonate. Sanghvi et al. [23] demonstrated that more vomiting during pregnancy was significantly associated with underweight children. Women with 
severe NVP associated with higher incidence of small-for-gestational-age babies and significantly lower birth weights.

In the present study, there were significant improvements of patients with nausea and vomiting that treated with ondansetron when compared with patient treated with pyridoxine [75 women [96.2\%] in group I versus 41 [52.6\%] in group II. These results agreed with Abas et al. [24], Kashifard et al. [25] and Oliveira et al. [9], that shown ondansetron is better than doxylamine plus pyridoxine in improvement of nausea and vomiting during pregnancy, both had fewer adverse effects than metoclopramide and both more effective for reduction of severe vomiting than metoclopramide. The meta-analysis by Tramer et al. [26] reported that $8 \mathrm{mg}$ dose of ondansetron was used to prevent nausea and vomiting during pregnancy. so, ondansetron $8 \mathrm{mg}$ was allowed for this study. Our study reported that ondansetron was effective in decreasing the incidence of nausea and vomiting.

Ondansetron also significantly reduced the need for additional antiemetic drugs during 0-6 hours after operation. However, it did not significantly decrease the need for additional rescue antiemetic use during 6-24 h after operation and, consequently, did not significantly decrease rescue antiemetic need over the total $24 \mathrm{~h}$ postoperative period [27].

Mayhall et al. [28] reported that administration of ondansetron among women act as a first line therapy, the majority did not have a history of NVP in pregnancy [91.4\%] and were not currently being treated for NVP [60.3\%]. Capp et al. [22] done their work on 36 women that half of them was taken ondansetron and other was taken combination of pyridoxine and doxylamine and reported that patients randomized to ondansetron demonstrated a greater reduction in nausea as compared to those taking pyridoxine and doxylamine $[p<0.05]$. Furthermore, women taking ondansetron reported less vomiting. Oliveira et al. [9] done their work on thirtysix women [eighteen in each group] were randomized to either ondansetron or pyridoxine plus doxylamine, of whom 13 [72\%] and 17 [94\%] completed follow-up, respectively. There were no differences changes among the groups as regard to demographic data or baseline nausea. Patients with ondansetron were more likely to have an improvement in their baseline NVP as compared with those using pyridoxine and doxylamine along the therapeutic course of five days. Furthermore, women using ondansetron had less vomiting when compared with another group. Thus, this work concluded that ondansetron is superior to the combination of pyridoxine and doxylamine in the treatment of nausea and emesis in pregnancy.

Ondansetron binds to $5-\mathrm{HT}_{3}$ receptors both in the central chemoreceptor trigger zone [CCR] and the gastro-intestinal tract [GIT] to inhibit emetic symptoms as nausea and has been generaly used to prevent postoperative nausea and vomiting. For example, a single dose of ondansetron before induction of anesthesia decreased post operative nausea in patients undergoing gynecological and obstetric surgery. Ondansetron was reported to be effective in preventing post operative nausea when added to a morphine-based PCA solution [29-30].

Pyridoxine [vitamin B6, pregnancy category A] considered a water-soluble vitamin that is involved in the metabolism of lipids, amino acids and carbohydrates. Doxylamine [pregnancy category B] directly inhibits the action of histamine at the $\mathrm{H} 1$ receptor, acts indirectly at the vestibular system, and exhibits some inhibition of muscarinic receptors to decrease stimulation of the vomiting center [31]. Matthews et al. [32] concluded that there is a lack of consistent evidence that pyridoxine is an effective therapy for NVP. Tan et al. [33] pyridoxine usage in $\mathrm{HG}$ did not demonstrate any improvement in nausea, vomiting or rehospitalisation in 46 women given 20 mg orally three times a day in addition to intravenous fluids. Pope et al.[34] demonstrated that the combination of doxylamine and pyridoxine was significantly more effective than pyridoxine alone.

Conclusion: Ondansetron was superior to the combination of pyridoxine and doxylamine for the reduction of nausea and vomiting occurring in pregnancy and also not associated with a significant increase in rate of major malformations in our analysis or abortion.

Limitations of this study: The small number of cases that meet the inclusion criteria. The study was divided by randomized study.

\section{Financial and Non-Financial Relationships and Activities of Interest}

None 


\section{REFERENCES}

1. Lee NM, Saha S. Nausea and vomiting of pregnancy. Gastroenterol Clin North Am. 2011; 40[2]:309-34. [DOI: 10.1016/j.gtc.2011.03.009].

2. Bustos M, Venkataramanan R, Caritis S. Nausea and vomiting of pregnancy - what's new? Auton Neurosci. 2017; 202, 62-72. [DOI: 10.1016/j.autneu.2016.05.002].

3. Zhang R, Persaud N. 8-Way Randomized Controlled Trial of Doxylamine, Pyridoxine and Dicyclomine for Nausea and Vomiting during Pregnancy: Restoration of Unpublished Information. PLOS ONE 2017; 12[1]: e0167609. [DOI: 10.1371/journal.pone].

4. Fejzo QM, Magtira A, Paik F, Macgibbon K. European Journal of Obstetrics and Gynecology and Reproductive Biology Neurodevelopmental delay in children exposed in utero to hyperemesis gravidarum. Eur J Obstet Gynecol, 2015; 3: 1-6. [DOI: 10.1016/j.ejogrb.2015.03.028].

5. Maltepe $\mathbf{C}$, Koren $\mathbf{G}$. Preemptive treatment of nausea and vomiting of pregnancy: results of a randomized controlled trial. Obstet Gynecol Int. 2013; 13:809787. [DOI: 10.1155/2013/809787].

6. Firouzbakht $M$, Nikpour M, Jamali B, Omidvar S. Comparison of ginger with vitamin $\mathrm{B} 6$ in relieving nausea and vomiting during pregnancy. Ayu. 2014; 35[3]:289-93. [DOI: 10.4103/0974-8520.153746].

7. Smith HS, Cox LR, Smith BR. Dopamine receptor antagonists. Ann Palliat Med. 2012; 1: 137-142. [DOI: 10. 3978/j.issn.2224-5820].

8. Koren G, Clark S, Hankins GD, Caritis SN, Miodovnik M, Umans JG, Mattison DR. Effectiveness of delayedrelease doxylamine and pyridoxine for nausea and vomiting of pregnancy: a randomized placebo-controlled trial. Am J Obstet Gynecol. 2010; 203[6]: 571-78. [DOI: 10.1016/j.ajog.2010.07.030].

9. Oliveira LG, Capp SM, You WB, Riffenburgh RH, Carstairs SD. Ondansetron compared with doxylamine and pyridoxine for treatment of nausea in pregnancy: a randomized controlled trial. Obstet Gynecol. 2014; 124:735-742. [DOI: 10.1097/AOG.0000000000000479].

10. Huang $X$, Choi Y, Hyung-Soon I, Yarimaga $O$, Yoon E, Kim H. Aspartate aminotransferase and Alanine Aminotransferase Detection Techniques. Sensors (Basel). $2006 \mathrm{Jul} ;$ 6(7): 756-782.

11. Cai A, Qi S, Su Z, Yang Y, Shen H, Wang T, Dai Y. Method Comparison and Bias Estimation of Blood Urea Nitrogen [BUN], Creatinine $[\mathrm{Cr}$ ], and Uric Acid [UA] Measurements Between Two Analytical Methods. Clin Lab., 2017; 63[1]:73-77. [DOI: 10.7754/ Clin. Lab.2016. 160536].

12. Ho WO, Krause S, McNeil CJ, Pritchard JA, Armstrong RD, Athey D, Rawson K. Electrochemical sensor for measurement of urea and creatinine in serum based on ac impedance measurement of enzymecatalyzed polymer transformation. Anal Chem. 1999; 71 [10]: 1940-6. [DOI: 10.1021/ac981367d].

13. Lee CY, Ratnapalan S, Thompson M. Unusual reactions to 5 -HT3 receptor antagonists in a child with rhabdomyosarcoma. Can J Clin Pharmacol. 2010; 17:14. [PMID: 20051608].
14. Christofaki M, Papaioannou A. Ondansetron: a review of pharmacokinetics and clinical experience in postoperative nausea and vomiting, Expert Opinion on Drug Metabolism \& Toxicology, 2014; 3: 437-444. [DOI: 10.1517/17425255.2014.882317].

15. D'Orazio LM, Meyerowitz BE, Korst LM, Romero R, Goodwin TM. Evidence against a link between hyperemesis gravidarum and personality characteristics from an ethnically diverse sample of pregnant women: a pilot study. J Womens Health [Larchmt] 2011; 20:137-44. [DOI: 10.1089/jwh.2009.1851].

16. Wood H, McKellar LV, Lightbody M. Nausea and vomiting in pregnancy: blooming or bloomin' awful? A review of the literature. Women Birth 2013; 26:100-4. [DOI: 10.1016/j.wombi.2012.10.001].

17. Yokoi A, Mihara T, Ka K, Goto T. Comparative efficacy of ramosetron and ondansetron in preventing postoperative nausea and vomiting: An updated systematic review and meta-analysis with trial sequential analysis. PLoS ONE, 2017; 12[10]: e0186006. [DOI: 10 10.1371/journal.pone.0186006].

18. Koren G, Shannon C, Hankins G, Caritis S. Maternal safety of the delayed-release doxylamine and pyridoxine combination for nausea and vomiting of pregnancy; a randomized placebo-controlled trial. Pregnancy and Childbirth 2015; 15:59-61. [DOI: 10.1186/s12884-0150488-1].

19. Pasternak B, Svanström H, Hviid A. Ondansetron in pregnancy and risk of adverse fetal outcomes. NEJM 2013; 368:814-23. [DOI: 10.1056/NEJMoa1211035].

20. Koren G, Madjunkova S, Maltepe C. The protective effects of nausea and vomiting of pregnancy against adverse fetal outcome-a systematic review. Reprod Toxicol Elmsford N 2014; 47 [14] 77-80. [DOI: 10.1016/ j. reprotox. 2014.05.012].

21. Dodds L, Fell DB, Joseph KS, Allen VM, Butler B. Outcomes of pregnancies complicated by hyperemesis gravidarum. Obstet Gynecol. 2006; 107:285-92

22. Capp S, Oliveira L, Carstairs S, You W. Ondansetron versus doxylamine/pyridoxine for treatment of nausea and vomiting in pregnancy: a prospective randomized double-blind trial. Am J Obstetr Gynecol. 2014;14: 39-42. [DOI: 10.1097/01.AOG. 0000195060.22832.cd].

23. Sanghvi U, Thankappan KR, Sarma PS, Sali N. Assessing potential risk factors for child malnutrition in rural Kerala, India. J Trop Pediatr. 2001; 47:350-5. [DOI: 10.1093/tropej/47.6.350].

24. Abas MN, Tan PC, Azmi N, Omar SZ. Ondansetron compared with metoclopramide for hyperemesis gravidarum: a randomized controlled trial. Obstet Gynecol. 2014; 123: 1272-1279. [DOI: 10.1097/AOG. 0000000000000242]

25. Kashifard M, Basirat Z, Kashifard M, GolsorkhtabarAmiri M, Moghaddamnia A. Ondansetron or metoclopramide? Which is more effective in severe nausea and vomiting of pregnancy? A randomized trial double-blind study. Clin Exp Obstet Gynecol. 2013; 40:127-130. [PMID: 23724526].

26. Tramer MR, Reynolds JM, Moore RA, McQuay HJ. Efficacy, dose-response, and safety of ondansetron in prevention of postoperative nausea and vomiting: a 
quantitative systematic review of randomized placebocontrolled trials. Anesthesiology, 1997; 87: 1277-1289. [DOI: 10.1097/00000542-199712000-00004].

27. Kim DR, Connolly KR, Cristancho P, Zappone M, Weinrieb RM. Psychiatric consultation of patients with hyperemesis gravidarum. Arch Womens Ment Health, 2009; 12: 61-67. [DOI: 10.1007/s00737-009-0064-7].

28. Mayhall EA, Gray R, Lopes V, Matteson KA. Comparison of antiemetics for nausea and vomiting of pregnancy in an emergency department setting. Am J Emerg Med. 2015; 33 [15] 882-886. [DOI: 10.1016/ j.ajem.2015.03.032].

29. Choi YS, Shim JK, Yoon DH, Jeon DH, Lee JY, Kwak YL. Effect of ramosetron on patient-controlled analgesia related nausea and vomiting after spine surgery in highly susceptible patients: comparison with ondansetron. Spine, 2008; 33: 602-6. [DOI: 10.1097/ BRS. 0b013e 31817c6bde].

30. Kim SY, Kim EM, Nam KH, Chang DJ, Nam SH, Kim KJ. Postoperative intravenous patient-controlled analgesia in thyroid surgery: comparison of fentanyl and ondansetron regimens with and without the non-steroidal anti-inflammatory drug ketorolac. Thyroid 2008; 18: 1285-90. [DOI: 10.1089/thy.2008.0007].

31. Spiegel DR, Webb K. A case of treatment refractory hyperemesis gravidarum in a patient with comorbid anxiety, treated successfully with adjunctive gabapentin: a review and the potential role of neurogastroentereology in understanding its pathogenesis and treatment. Innov Clin Neurosci. 2012; 9:31-38. [PMID: 23346516].
32. Matthews A, Dowswell T, Haas DM, Doyle M, O'Mathúna DP. Interventions for nausea and vomiting in early pregnancy. Cochrane Database Syst Rev. 2010; (9):CD007575. [DOI: 10.1002/14651858. CD007575. pub2].

33. Tan PC, Yow CM, Omar SZ. A placebo-controlled trial of oral pyridoxine in hyperemesis gravidarum. Gynecol Obstet Invest. 2009; 67:151-7. [DOI: 10.1159/ 0001 81182].

34. Pope E, Maltepe C, Koren G. Comparing pyridoxine and doxylamine succinate-pyridoxine $\mathrm{HCl}$ for nausea and vomiting of pregnancy: A matched, controlled cohort study. J Clin Pharmacol., 2015;55:809-14. [DOI: 10. 1002/jcph.480].

35. Choi HJ, Bae YJ, Choi JS, Ahn HK, Hong DS, Yun J, Han J. Evaluation of nausea and vomiting in pregnancy using the Pregnancy-Unique Quantification of Emesis and Nausea scale in Korea. Obstet Gynecol Sci. 2018 Jan; 61[1]: 30-37. [DOI: 10.5468/ogs.2018.61.1.30]. 